\title{
A EFICÁCIA DOS DIREITOS
}

\section{FUNDAMENTAIS NO QUE SE}

\section{REFERE ÀS ATIVIDADES EXERCIDAS}

PELO PODER PÚBLICO E PELOS ENTES PRIVADOS

ÂNGELA MARIA RIBEIRO PRUDENTE 


\title{
A EFICÁCIA DOS DIREITOS FUNDAMENTAIS NO QUE SE REFERE ÀS ATIVIDADES EXERCIDAS PELO PODER PÚBLICO E PELOS ENTES PRIVADOS ${ }^{1}$
}

\author{
Ângela Maria Ribeiro Prudente ${ }^{2}$
}

\section{RESUMO}

A Constituição Federal brasileira não dispõe expressamente acerca da vinculação dos entes públicos e privados às normas de direitos fundamentais. Con tudo, tem-se interpretado o artigo $5^{\circ}, \S 1^{\circ}$, da Carta da forma mais ampla possível, de tal sorte que sua eficácia e abrangência surta efeitos também nos poderes públicos e privados. Ainda é bastante discutido na doutrina a esfera de abrangência de alguns direitos fundamentais, posto que não se consegue definir ao certo se tal dispositivo encontra-se no campo público ou privado. Assim, tem-se que analisar cada direito fundamental focando sempre em quem está diretamente vinculado à norma, se diz respeito à pessoa pública ou privada. De qualquer maneira, a observância das normas de direitos fundamentais do cidadão certamente perfazem o caminho correto para a efetivação de um Estado Democrático de Direito onde o cidadão desfrutará de uma vida digna e justa.

\section{Palavras-chave:}

Constituição Federal, Direitos Fundamentais, Vinculação, Poder Público, Ente Privado.

\section{ABSTRACT}

The Brazilian Federal Constitution does not use expressly concerning on entailing the public and private beings to the norms of basic rights. However, the article has been interpreted $5^{\circ}, \S 1^{\circ}$, of the Letter of the possible form amplest, of such luck that its effectiveness and also ri-

\footnotetext{
${ }^{1}$ Texto elaborado com a finalidade de discernir a aplicação das normas atinentes aos direitos fundamentais na esfera pública e privada.

${ }^{2}$ Acadêmica da disciplina de Monografia do Curso de Pós-Graduação em Direito Constitucional em 2008.
} 
ches occasional effect in being able on public and private issues. Still sufficiently it is argued in the doctrine the sphere of the riching of some basic rights, rank that if does not obtain to define to the certainty if such device meets in the public or private field. Thus, it is had that to always analyze each basic right on focus into who directl it is tied with the norm, if says respect the public entity or private. In any way, the observance norms of basic rights it citizen certainly rich the correct way for the made of a Democratic State of Right where the citizen will be able to enjoy of a worthy life and joust.

\section{Key-words:}

Federal Constitution, Fundamental Rights, Tie, Public System, Private Enthe.

\section{INTRODUÇÃO}

A subordinação dos poderes públicos e das entidades privadas aos direitos e garantias fundamentais do cidadão, consagrados na Carta Política Pátria, de 1988, segue vinculada a matéria da eficácia e da aplicabilidade, vez que esta vinculação é necessária para que a norma tenha eficácia e, consequentemente, aplicabilidade.

A Constituição da República tratou da questão da aplicabilidade dos direitos e garantias fundamentais em seu art. $5^{\circ}, \S 1^{\circ}$, onde dispõe acerca do princípio da aplicação imediata das normas de direitos fundamentais.

Na seara pública, as normas de direitos e garantias fundamentais devem ser obrigatoriamente observadas no desempenho das funcões típicas e atípicas dos três Poderes do Estado.

Nesse contexto, se alguma norma editada ferir alguns dos direitos fundamentais do cidadão, esta estará sujeita a ação pertinente acerca do controle de constitucionalidade para a devida averiguação da sua constitucionalidade. Na esfera privada, onde as empresas e estabelecimentos comerciais regem, por meio de estatutos e regu- 
lamentos, sua organização interna, os procedimentos para sua positivação deverão estar também em conformidade com os direitos e garantias fundamentais.

Ainda em relação aos entes privados, os direitos fundamentais funcionam no sentido de proteger o cidadão de possíveis atrocidades do Estado, bem como do maior poder econômico de terceiros particulares. Assim, visa proteger o homem de uma possível tirania pública e de seus semelhantes que objetivem, de alguma forma, privá-lo de sua liberdade e dos elementos necessários para uma vida digna.

\section{AS ATIVIDADES DO PODER PÚBLICO NO SISTEMA DA TRIPARTIÇÃO DOS PODERES, CONSAGRADOS NA CARTA CONSTITUCIONAL DE 1988, E SUA VINCULAÇÃO AOS DIREITOS E GARANTIAS FUNDAMENTAIS.}

Diferentemente de algumas Constituições Federais estrangeiras, como é o caso da Portuguesa (art. 18/1), da Alemã (art. $1^{\circ}$, Inc. Ill) e da Espanhola (art. 53.1), a Constituição-Federal Pátria não dispôs expressamente acerca da vinculação das entidades públicas aos direitos fundamentais do cidadão.

Contudo tal omissão da Constituição brasileira não representa a exclusão dos poderes públicos e privados da subordinação de seus ordenamentos aos direitos fundamentais. Isso se dá em razão da amplitude da interpretação que deve ser adotada ao analisar o art. $5^{\circ}, \S$ $1^{\circ}$, da Constituição Federal, a qual impele ser a mais ampla possível.

Portanto, deve ser o art. $5^{\circ}, \S 1^{\circ}$, da Carta, interpretado de forma abrangente, para que cada e qualquer ato dos poderes públicos tenha os direitos fundamentais como "baliza e referencial".

A abrangência da obediência das normas públicas em relação aos direitos fundamentais estende-se também aos órgãos co-ligados ou institucionalizados dentro de qualquer dos Poderes do Estado. Assim, tem-se a vinculação aos direitos fundamentais também estendida a todos os órgãos funcionais dos Poderes, independentemente 
da função em questão ser típica ou atípica. 0 efeito vinculante dos direitos fundamentais alcança não apenas cada pessoa jurídica de direito público, mas também as pessoas jurídicas de direito privado que, nas suas relações com os particulares, dispõem de atribuições de natureza pública, assim como pessoas jurídicas de direito público na sua atuação na esfera privada. ${ }^{3}$

\subsection{A SUBORDINAÇÃO DAS ATIVIDADES LE- GISLATIVAS AOS DIREITOS E GARANTIAS FUNDAMENTAIS}

A possibilidade de controle de constitucionalidade das normas editadas pelo poder público também consagra a vinculação das normas editadas pelo Poder Legislativo, aos direitos fundamentais.

Assim, por terra caiu, ao menos no Direito brasileiro, a crença da onipotência do legislador estatal, onde este era revestido de todo poder necessário para fazer valer o interesse do governo no regimento da sociedade.

Com o advento da Carta Republicana de 1988 o Constituinte priorizou a existência de normas intangíveis, de cunho de interesses e garantias fundamentais, não podendo ser modificadas ou contrariadas em face do Direito Positivo.

Essa obediência a qual o Poder Legislativo está sujeito não se restringe apenas a normas de cunho de direitos e garantias fundamentais, mas também a toda estrutura positivada no texto constitucional. $^{4}$

Não há mais que se discutir os direitos e garantias fundamentais perante a lei, mas sim esta para com aqueles.

De pronto, verifica-se que a vinculação aos direitos fundamentais significa para o legislador uma limitação material de sua liber-

${ }^{3}$ Cf., J. Miranda, Manual IV, p. 281.

${ }^{4}$ Cf., P. M. V. G. Patto, in: DDC n. 33-34 (1988), p. 487. 
dade de conformação no âmbito de sua atividade regulamentadora e concretizadora. 5

Quer-se com toda proteção atribuída aos direitos fundamentais do cidadão, consagrados em uma Carta Republicana, a limitação das possibilidades restritivas do legislador atinente a vida social digna do cidadão, procurando-se evitar abusos de poder bem como injustiças.

Em relação ao poder de legislar, a vinculação expressa no artigo $5^{\circ}, \S 1^{\circ}$, da Constituição gera dois efeitos significativos na seara funcional do Poder Legislativo, um lado negativo e o outro positivo.

No sentido negativo, também conhecido como proibitivo, há o controle de novas normas, de tal sorte que estas não venham a ser editadas e publicadas contendo dispositivos que ferem de algum modo, a Constituição Federal, principalmente no que tange aos direitos e garantias fundamentais.

Na seara positivista, a vinculação das leis ao sistema constitucional dos direitos e garantias fundamentais prevê a atenção a estes princípios em toda cadeia jurídica do ordenamento normativo, assumindo, os direitos fundamentais, a função de princípio de toda ordem jurídica.

\subsubsection{A PROBLEMÁTICA DA INCONSTITUCIONALIDADE POR OMISSÃO}

0 problema da inconstitucionalidade por omissão tem sua fonte na inércia do legislador em face de uma ordem presente nas normas de direitos fundamentais na Constituição Federal.

Sua eficácia varia de acordo com a densidade normativa e grau de concretude destas normas.

Assim, o princípio da aplicabilidade imediata, consagrado no artigo $5^{\circ}, \S 1^{\circ}$, da Constituição Federal alcança todos os direitos funda-

${ }^{5}$ Cf., K. Hesse, in: EuGRZ 1991, p. 429. 
mentais, inclusive os sociais.

Contudo, é necessário observar que as normas de direitos fundamentais sociais não possuem eficácia inteiramente imediata, ficando vinculadas a atividade legislativa, sendo, portanto, suas normas de eficácia limitada, pois dependem da atividade do Poder Legislativo para que tenham a plena eficácia.

\subsection{A VINCULAÇÃO DO EXECUTIVO AOS DIREITOS FUNDAMENTAIS}

Da mesma forma do legislativo, o Poder Executivo também se encontra vinculado às normas de direitos fundamentais do cidadão.

Isso se deve à força vinculante do artigo $5^{\circ}, \S 1^{\circ}$, da Constituição Federal que, como já visto, deve ser interpretado de forma ampla, exercendo, então abrangência também sobre todos os poderes públicos, inclusive o Poder Executivo. Assim, imperioso se faz discutir se o efeito vinculante dos órgãos da administração aos direitos fundamentais põe em exercício o princípio da constitucionalidade imediata da administração, o que significa que os órgãos administrativos

' devem exercer apenas as normas que se encontram em conformidade com os direitos fundamentais, bem como executar estas leis de forma a não ferir o disposto na Constituição Federal, aplicando-as e interpretando-as em conformidade com os direitos fundamentais. Caso contrário, os atos administrativos que não venham a observar tais postulados estarão sujeitos a invalidação judicial, levando a ineficácia de suas disposições.

0 que se quer, com todos os aparatos regenciais das normas e atividades públicas é fazer com que estes exercícios obedeçam ao disposto na Constituição, segundo a ordem de valores nela contida. Por tal razão, a Carta Política Pátria, de 1988, é conhecida mundialmente por ser uma Carta Cidadã, ao passo que defende, em seus princípios basilares, todas as ferramentas necessárias para a vida digna do cidadão.

Nesse espeque, poderão os órgãos da administração recusar-se 
a executar normas tidas como inconstitucionais, mesmo que já se encontrem em prática no meio legislativo.

A administração pública tem como princípio basilar, dentre outros, o da legalidade, pelo qual deve obediência às normas, desde que legalmente em vigor.

Contudo, a administração pública deve maior obediência ao princípio da constitucionalidade, visto a posição hierárquica suprema que a Constituição Federal exerce sobre todas as demais normas regentes do Estado.

Todavia, há de se ressaltar que não é competência dos órgãos administrativos do Poder Executivo fazer o controle de constitucionalidade de normas de obediência duvidosa a Constituição Federal. Assim, compete a esses órgãos administrativos, do Executivo, obediência estrita as ordens de seus órgãos hierarquicamente superiores, até que sobrevenha decisão judicial acerca da constitucionalidade da norma até então tida como inconstitucional.

Nesse contexto, há uma possibilidade excepcional do exercício de urn controle de constitucionalidade, realizado pelos órgãos administrativos, já que estes não devem obediência incondicional à lei.

Nas hipóteses de grosseira afronta legislativa aos direitos fundamentais poderá o órgão administrativo recusar-se a aplicar a norma, mesmo que tal desídia contrarie ordem superior, podendo ocorrer restritamente aos seguintes casos: a) quando a aplicação da lei implicar a prática de um crime, especialmente nos casos em que resultar uma ofensa aos direitos à vida e a integridade pessoal, que nem mesmo em caso de estado de sítio ou de defesa podem ser suspensos; b) quando as leis violarem o núcleo essencial dos direitos fundamentais, de modo especial quando levarem ao aniquilamento dos direitos à vida e a integridade pessoal, por tratar-se de hipóteses nas quais as leis podem ser consideradas inexistentes. ${ }^{6}$

${ }^{6}$ Cf., J. J. Canotilho, Direito Constitutional, p. 596-7. 
Assim, o órgão administrativo, no que tange ao cumprimento dos direitos fundamentais, poderá sim recusar-se a aplicar a lei sempre que a ofensa a um direito fundamental for evidente, nos casos acima enumerados.

Para tanto, é necessário que o ente público observe atentamente o caso concreto, devendo tomar tal decisão quando não houver dúvida alguma acerca da inconstitucionalidade da norma. Caso contrário, havendo dúvida quanto a este aspecto, deverá dar guarida à corriqueira presunção de constitucionalidade do ato legislativo.

\subsubsection{CONSIDERAÇÕES QUANTO À VINCULAÇÃO DO PODER PÚBLICO NO QUE CONCERNE AOS DIREITOS FUNDAMENTAIS SOCIAIS}

Se, na esfera dos direitos fundamentais, a vinculação dos órgãos públicos aos direitos fundamentais é absoluta, no que concerne aos direitos sociais, previstos no Capítulo II do Titulo II da Constituição Federal, esta vinculação é relativa.

A garantia, contida no artigo $5^{\circ}, \S 1^{\circ}$, da Constituição, é aplicável a todos os direitos fundamentais, inclusive aos sociais. Contudo, para aqueles é absoluta e, para estes, relativa.

A Constituição, em matéria de direitos fundamentais, como já foi discutido, prevê normas com eficácia imediata. Entretanto, os direitos fundamentais, de cunho especificamente social, encontram-se em posição menos privilegiada, no que tange a sua vinculação ao exercício dos poderes públicos.

Nestes casos, tais normas possuem eficácia limitada, onde caberá ao legislador regular as questões desta natureza, quando Ihe interpostas.

Assim, não podem ser considerados plenos os direitos fundamentais sociais, pois estes deverão ser ainda regulados e limitados pelo Legislativo.

Como Incumbe ao Poder Legislativo, dentre suas prerrogativas 
constitucionais, a divisão dos recursos para as mais variadas áreas sociais, mediante, evidentemente, o devido processo legal, muitas áreas encontram-se carentes de recursos, o que faz com que seu desenvolvimento fique prejudicado em função da necessidade de manutenção da máquina pública bem como da divisão de verbas para todas as áreas do governo.

Assim, não é possível atender de imediato a todos os anseios e necessidades sociais do país, mas, por um processo de desenvolvimento, tem-se tentando, a longo prazo, abarcar todas as necessidades sociais existentes, procurando-se cumprir o disposto na Constituição Federal.

\subsection{AS ATIVIDADES DO JUDICIÁRIO E SUA VINCULAÇÃO COM OS DIREITOS FUNDAMENTAIS}

No que diz respeito à vinculação das prerrogativas atribuídas ao Poder Judiciário aos direitos fundamentais, pode-se afirmar que suas atividades funcionais encontram-se diretamente ligadas a estes preceitos fundamentais, devendo suas decisões ter seus fundamentos basilares no disposto na Carta Constitutional.

No que tange as atividades funcionais do Poder Judiciário, este encontra-se atrelado aos direitos e as garantias fundamentais. Isso se deve, primeiramente, ao fato do Judiciário possuir a prerrogativa de decidir sobre a vida dos particulares, fazendo cumprir taxativamente o disposto na Constituição.

Além disso, o Poder Judiciário é incumbido de realizar o controle de constitucionalidade das normas editadas que, pelo princípio da simetria, tal prerrogativa compete a seus tribunais de cúpula, de acordo com a esfera de abrangência da norma em discussão.

Nesse contexto, pode-se afirmar que são dos órgãos do Poder Judiciário que emanam as diretrizes legislativas e jurídicas a serem adotadas pelos demais Poderes, ditando tendências jurisdicionais, fornecendo o Conteúdo e sentido corretos a serem utilizados na in- 
terpretação e aplicação dos direitos fundamentais.

Assim, ao Poder Judiciário, desde os juízes de primeiro grau aos tribunais superiores, cabe definir o sentido da aplicação, interpretação e integração das normas fundamentais, dando a estas a maior eficácia possível dentro do universo Jurídico?

Ao Poder Judiciário também compete verificar se as normas de direitos fundamentais estão sendo devidamente observadas pelos particulares, devendo assim incluir no próprio ofício esta análise, nos litígios levados a apreciação de seus órgãos jurisdicionais.

Nessa seara, constata-se que os direitos fundamentais constituem, ao mesmo tempo, parâmetros materiais e limites para o desenvolvimento judicial do direito. ${ }^{8}$

Dessa forma, verifica-se também que o Judiciário possui o poder, bem como o dever, de não aplicar as normas inconstitucionais que, em um eventual conflito entre os princípios da legalidade e da constitucionalidade (isto é, entre lei e Constituição), acaba por resolver-se em favor do último. ${ }^{9}$

No que concerne à aplicação do disposto nos direitos fundamentais sociais, o Poder Judiciário, no exercício de suas funções, deparando-se a um caso concreto de aplicação da referida norma constitutional, deverá analisar o disposto na Constituição de maneira menos rígida, que decorre da menor densidade normativa destas normas ao nível da Constituição, já que tais normas derivam da atividade legislativa, não podendo o Judiciário interferir em tal prerrogativa funcional atribuída ao Poder Legislativo pela Constituição Federal. ${ }^{10}$

Ainda na esfera vinculativa dos juízes e tribunais aos direitos fundamentais, não se poderá perder de vista que os próprios atos judiciais que atentem contra os direitos fundamentais poderão consti-

\footnotetext{
${ }^{7}$ Cf J. Miranda, Manual IV, p. 283-4.

${ }^{8}$ BK, art. 1, p. $12 / 1$.

${ }^{9}$ Cf., J.J. Gomes Canotilho, Direito Constitucional, p. 600.

${ }^{10}$ Cf., I. W. Sarlet, A Eficácia dos Direitos Fundamentais, p. 397.
} 
tuir objeto de controle jurisdicional. Fiscalização esta que é exercida em última instância pelo Supremo Tribunal Federal, na condição de autêntica Corte Constitucional. ${ }^{11}$

\section{A QUESTÃO DA VINCULAÇÃO DE PARTICULARES ÀS NORMAS DE DIREITOS E GARANTIAS CONSTITUCIO- NAIS}

Além de se vincularem a todos os poderes públicos, os direitos fundamentais também exercem eficácia vinculante no âmbito das relações jurídicas entre particulares.

Assim, têm-se os direitos fundamentais destinados ao poder público, como é o caso do habeas corpus, e aos entes privados, como é o caso do sigilo telefônico.

0 mesmo ocorre também para os direitos fundamentais sociais, especialmente o que diz com os direitos dos trabalhadores, que têm por destinatário os empregadores, geralmente, particulares. ${ }^{12}$

Contudo, ainda não é pacífico na doutrina e na jurisprudência pátrias uma definição correta de todos os direitos fundamentais se, públicos ou privados.

De qualquer forma, sabe-se que a lei é antropocêntrica. Logo, é pensada e criada tendo o homem como escopo, como objetivo final. Assim, mesmo ainda não sendo transparente se a vinculação de determinado direito fundamental se destina ao poder público ou aos entes privados, sabe-se que, pelo menos, direta ou indiretamente, procura abarcar as necessidades fundamentais do homem, constitucionalmente tido por cidadão.

Portanto, com a promulgação de direitos fundamentais em um texto constitutional, até como direitos de defesa, visa-se

\footnotetext{
${ }^{11}$ Cf., também I. W. Sarlet, A Eficácia dos Direitos Fundamentais, p. 398.

${ }^{12}$ Cf., também I. W. Sarlet, A Eficácia dos Direitos Fundamentais, (2007) p. 400.
} 
proteger o indivíduo de ingerências por parte dos poderes públicos na esfera pessoal. Contudo, observa-se também que, com a consolidação de um Estado Democrático de Direito, onde o sistema econômico predominante é o capitalista, esta proteção constitucional estende-se também aos detentores de poder social e econômico.

Assim, há que acolher, portanto, a lição de Vieira de Andrade, quando destaca os dois aspectos principais e concorrentes da problemática, quais sejam, a constatação de que os direitos fundamentais, na qualidade de princípios constitucionais e por força do princípio da unidade do ordenamento jurídico, se aplicam relativamente a toda ordem jurídica, inclusive privada, bem como a necessidade de se protegerem os particulares também contra atos atentatórios aos direitos fundamentais provindos de outros indivíduos ou entidades particulares ${ }^{13}$.

Dessa forma, há aqueles que afirmam serem os direitos fundamentais apenas direitos de defesa, contra o Estado, logo, o cidadão encontra-se indiretamente vinculado a norma.

Em outra corrente, defende-se que os direitos fundamentais constituem normas basilares para toda ordem jurídica, bem como da força normativa da Constituição, não podendo haver concepções paralelas ao entendimento desta, fazendo-se, por si só, auto-aplicável.

0 que se percebe, desde logo, na esteira da melhor doutrina, e a inexistência de soluções uniformes nesta seara, ${ }^{14}$ já que a eficácia direta ou indireta apenas pode ser aferida à luz do caso concreto, dependendo, em princípio, da existência de uma norma de direito privado e da forma como esta dispõe sobre as relações entre os particulares, destacando-se as seguintes hipóteses: a) poder-se-á sustentar que a concretização de determinadas normas de direitos

${ }^{13}$ Cf., J. C. Vieira de Andrade. Os Direitos Fundamentais, p. 274

${ }^{14}$ Cf., a oportuna lembrança de J. J. Canotilho, Direito Constitucional, p. 607. 
fundamentais por intermédio do legislador ordinário leva a uma aplicação indireta da Constituição na esfera das relações privadas, no sentido de uma aplicação mediada pelo legislador, que, na edição das normas de direito privado, deve cumprir e aplicar os preceitos relativos aos direitos fundamentais; ${ }^{15}$ b) uma aplicação indireta da Constituição também se verifica quando o legislador ordinário estabeleceu cláusulas gerais e conceitos indeterminados que devem ser preenchidos pelos valores constitucionais, de modo especial os contidos nas normas de direitos fundamentais. ${ }^{16}$ Por derradeiro, estar-se-á em face de uma aplicação direta da Constituição quando inexistir lei ordinária concretizadora, quando não houver cláusulas gerais ou conceitos indeterminados aplicáveis à espécie ou mesmo quando o seu campo de aplicação for mais restrito do que o das normas constitucionais. ${ }^{17}$ Por fim, constata-se que as normas de direito privado não podem contrariar o conteúdo dos direitos fundamentais, impondo-se uma interpretação das normas privadas conforme os parametros axiológicos contidos nas normas de direitos fundamentais, o que habitualmente ocorre quando se trata de aplicar conceitos indeterminados e cláusulas gerais de direito privado. ${ }^{18} \mathrm{Assim}$, os direitos fundamentais influenciam no direito privado por meio das normas que regulam cada área específica do direito.

\section{CONSIDERAÇÕES FINAIS}

É certo que, para que urn Estado Democrático de Direito prospere, este deve possuir normas fortes tanto em efetividade quanto em

\footnotetext{
${ }^{15}$ Cf., J. J. Gomes Canotilho, Direito Constitucional, p. 609.

${ }^{16}$ Cf., V. M. P. D. Pereira da Silva, in: RDP n. 82 (1987), p. 46.

${ }^{17}$ Cf., também, V. M. P. D. Pereira da Silva, in: RDP n. 82 (1987), p. 46.

${ }^{18}$ Cf., K. Hesse, Grundzüge, p. 155, in: A Eficácia dos Direitos Fundamentais, I. W. Sarlet (2007), p. 406.
} 
cumprimento, visando sempre a integridade moral e a justiça.

Assim, o legislador da Constituinte de 1988 propôs incluir em um texto constitucional direitos e garantias fundamentais para uma vida digna do cidadão.

Porém, de nada adianta normas e postulados se não houver por parte dos obrigados o efetivo cumprimento do disposto legislativo.

Dessa forma, a Carta Política Pátria, de 1988, procurou consolidar o cumprimento do disposto nos direitos fundamentais do cidadão incluindo, em seu artigo $5^{\circ}, \S 1^{\circ}$, o princípio que, apesar de não expresso, e amplamente compreendido pelo ordenamento, vincula as atividades dos poderes públicos e das entidades privadas aos direitos fundamentais do cidadão.Assim, as atividades de todos os poderes do Estado, na sua forma legislativa, executiva e judiciária estão vinculadas ao que dispõe a Carta acerca dos direitos fundamentais do cidadão. Contudo, ainda pairam sobre a questão discussões acerca do cumprimento por parte do Estado das normas de direitos fundamentais sociais, onde, muitas vezes, o Estado peca por omissão.

Incluídos ainda nos dispositivos que dispõem acerca do cumprimento dos direitos fundamentais encontram-se os entes privados, onde visa-se dar garantias ao cidadão de que direitos básicos à liberdade e à livre expressão, por exemplo, serão respeitados, tanto pelo ente público, quanto pelos privados, mesmo que com maior potência social e financeira.

Os direitos e garantias fundamentais perfazem uma importante ferramenta na consolidação do Estado Democrático de Direito, onde há o revestimento do cidadão com dispositivos constitucionais próprios para fazer com que esses direitos sejam realmente efetivados, dando cumprimento à vontade do legislador constituinte. 


\section{REFERÊNCIAS BIBLIOGRÁFICAS}

ANDRADE, José Carlos Vieira de. Os Direitos Fundamentais na Constituição Portuguesa de 1976, Coimbra: Livraria Almedina, 1987.

BONAVIDES, Paulo. “A Revisão Constitucional na Carta de 1988", in: Revista de Informação Legislativa n. 116 (1992), p. 21 e ss.

BRASIL, Constituição (1988). Constituição da República Federativa do Brasil. Brasília: Senado Federal, Subsecretaria de Edições Técnicas, 2005. 436p.

. Curso de Direito Constitucional, 7. ed., São Paulo: Ed. Malheiros, 1997.

Direito Constitucional, 19ª ed. São Paulo: Ed. Atlas, 2006.

CANOTILHO, Joaquim José Gomes. Direito Constitucional, 5. ed., Coimbra: Livraria Almedina, 1992.

HESSE, Konrad. A Força Normativa da Constituição, Porto Alegre: Fabris, 1991. MIRANDA, Jorge. Manual de Direito Constitucional, vol. IV, 2. ed., Coimbra: Coimbra, 1993.MORAES, Alexandre. Direitos Humanos Fundamentais. São Paulo: Ed. Atlas, 1998.

PATTO, Pedro Maria Godinho Vaz. "A Vinculação das Entidades Públicas pelos Direitos, Liberdades e Garantias", in: Documentação e Direito Comparado. 33-34(1998), p. 474 e ss.

SARLET, Ingo Wolfgang. A Eficácia dos Direitos Fundamentais: 7. ed. Porto Alegre: Ed. Livraria do Advogado, 2007.

SILVA, Virgílio Afonso da. A Constitucionalização do Direito. Os direitos fundamentais nas relações entre particulares, São Paulo: Malheiros, 2005. 